\title{
Prostate cancer and obesity in Arab countries.
}

\author{
Ihab Ahmed Hekal \\ Department of Urology, MDH Hospital, Al-khobarM, Kingdom of Saudi Arabia
}

Accepted October 18, 2018

\section{Letter to the Editor}

In western experience; Prostate cancer (PCa) is a major health problem. It is the second most diagnosed cancer; it is ranked as sixth most common fatal malignancy of men [1].

In USA, two-thirds of men classified as overweight and onethird as obese [2].

Obesity is linked to increased risk of death from numerous cancer types including $\mathrm{PCa}$ [3-5].

In Arabic and Middle East countries there is no robust epidemiological data of PCa prevalence, however some studies had shown lower rate in comparison to western countries [6].

Low prostate cancer rate among Arab countries could be attributed to genetic factors [7], dietary factors [8] or hormonal androgenic factors [9].

Therefore, we may need to focus on the PCa and Obesity in Middle East and Arab patients.

Another interesting point is obesity and higher Body Mass Index with comparison of PSA (prostate specific antigen), had approved inverse correlation in many studies $[10,11]$.

Indeed, the prevalence of obesity in Arab countries has no published figure. However, with high prevalence due to increased incidence of Diabetic patients, it could miss $\mathrm{PCa}$ cases due to their low PSA. Moreover, obesity is considered as risk factor on prostatic biopsies [12].

Measured PSA is demonstrating low level in Arab countries as shown by Kamal et al [13]. Even a recommendation to decrease the diagnostic PSA-cutoff point was suggested to avoid missing positive cases, thus Serum PSA $2 \mathrm{ng} / \mathrm{ml}$ is recommended as a cut-off point to screen and biopsy advice for non symptomatic patients $<50$ years [14].

With the aura of PSA and BMI inverse relationship, authors tried to find a correlation or equation to predict the actual PSA as sole best screening test up till now.

Kim et al. found that the correlation between PSA and BMI, based on 60 years age stratification, was significant inverse relation in younger patients only and not with the older patients [15]. On other hand, in another study, coincidence finding between PSA and BMI was observed as direct relation in patients less than 50 years of age, whereas PSA is less than 4 $\mathrm{ng} / \mathrm{ml}[16]$.

Later on, a new suggested equation is suggested to adjust PSA based on BMI and Age [17].

To the date, we still depend on PSA and prostatic biopsies as high sensitivity tools to diagnose $\mathrm{PCa}$, which are need optimization to be applied on Arabic nations.
For instance, some Asian countries are suggesting new PSA adjustments for screening of their population, might be lower than the international figure of PSA $[17,18]$.

As a conclusion, it is robust the need for further studies on Arab countries to emphasize their prevalence of PCa, PSA and obesity correlation. This could be either specific PSA cutoff point, applying certain tumor molecular markers, verification of certain correction equations and/ or define Age/BMI/ PSA stratification for those groups of patient.

Personally, I believe there is still much work is needed in this concern.

\section{References}

1. Center MM, Jemal A, Lortet-Tieulent J, et al. International variation in prostate cancer incidence and mortality rates. Eur Urol. 2012;61:1079-92.

2. Flegal KM, Carroll MD, Ogden CL, et al. Prevalence and trends in obesity among US adults, 1999-2008. JAMA. 2010;303:235-41.

3. Calle EE, Rodriguez C, Walker-Thurmond $\mathrm{K}$, et al. Overweight, obesity, and mortality from cancer in a prospectively studied cohort of U.S. adults. N Engl J Med. 2003;348:1625-38.

4. Reeves GK, Pirie K, Beral V, et al. Cancer incidence and mortality in relation to body mass index in the Million Women Study: cohort study. BMJ. 2007;335:1134.

5. Renehan AG, Tyson M, Egger M, et al. Body-mass index and incidence of cancer: A systematic review and meta-analysis of prospective observational studies. Lancet 2008;371:56978.

6. Prostate cancer in Arab Population: An Overview: Saudi Medical Journal 2018 (Article in Press).

7. Alyaiya AA. Proteomics-based signature for human benign prostate hyperplasia and prostate adenocarcinoma. Int $\mathrm{J}$ Oncol. 2011;38:1047-57.

8. Hamalainen E, Adlercreutz H, Puska P, et al. Diet and serum sex hormones in healthy men. J Steroid Biochem. 1984;20:459-64.

9. Kehinde EO. Do differences in age specific androgenic steroid hormone levels account for differing prostate cancer rates between Arabs and Caucasians? Int J Urol. 2006;13:354-61.

10. Hekal IA, Ibrahiem EI. Obesity-PSA relationship: A new formula. Prostate Cancer Prostatic Dis. 2010.13:186-90. 
11. Kristal AR, Chi C, Tangen CM, et al. Associations of demographic and lifestyle characteristics with prostatespecific antigen (PSA) concentration and rate of PSA increase. Cancer 2006;106:320-8.

12. Freedland SJ, Wen J, Wuerstle M, et al. Obesity is a significant risk factor for prostate cancer at the time of biopsy. Urology 2008;72:1102-5.

13. Kamal BA. Prostate specific antigen reference ranges in Saudi men. Saudi Med J. 2003;24:665-8.

14. Hekal IA. The patients less than 50 years: Is there a need to lower the PSA cutoff point? Prostate Cancer Prostatic Dis. 2009;12:148-51.
15. Kim YJ, Han BK, Hong SK, et al. Body mass index influences prostate-specific antigen in men younger than 60 years of age. Int J Urol. 2007;14:1009-12.

16. Hekal IA, Ibrahiem EI. Obesity-PSA relationship: A new formula. Prostate Cancer Prostatic Dis. 2010;13:186-90.

17. Lee SE, Kwak C, Park MS, et al. Ethnic differences in the age-related distribution of serum prostate-specific antigen values: A study in a healthy Korean male population. Urology. 2000;56:1007-10.

18. He D, Wang $M$, Chen $\mathrm{X}$, et al. Ethnic differences in distribution of serum prostate-specific antigen: a study in a healthy Chinese male population.Urology. 2004;63:722-6.

\section{*Correspondence to:}

Ihab Ahmed Hekal

Department of Urology

MDH Hospital

Al-khobar M

Kingdom of Saudi Arabia

E-mail: eahekal@yahoo.com 